\title{
CORRECTION
}

\section{Identification and management of frailty in the primary care setting}

CMAJ has been made aware of an error and omission that occurred in the Sept. 24, 2018, issue. ${ }^{1}$

Dr. Elsa Dent's affiliation was listed as "Torrens University of Adelaide, Adelaide, South Australia" and should have been listed as "Torrens University Australia, Adelaide, Australia; Baker Heart and Diabetes Institute, Melbourne, Australia."

This has been corrected at cmaj.ca.

- Cite as: CMAJ 2019 January 14;191:E54. doi: $10.1503 / \mathrm{cmaj} .181707$

\section{Reference}

1. Abbasi M, Rolfson D, Khera AS, et al. Identification and management of frailty in the primary care setting. CMAJ 2018;190:E1134-40. 